Skeletal metastases are severe complications in the course of cancer, and they indicate a worse prognosis. The use of modern imaging techniques allows rapid diagnosis of bone metastases. Properly selected diagnostic imaging (scintigraphy, positron emission tomography, whole body MRI) allows us to evaluate the number of metastatic foci in the skeletal system. Complementary imaging examinations (X-ray, computed tomography, magnetic resonance imaging) determine the extent of metastasis and its character: osteolytic, osteoblast, mixed). Hypercalcaemia is a symptom of low specificity for metastatic bone disease (a result of osteolysis); nevertheless, it is a significant complication in oncological treatment and worsens the prognosis of the patient. A biopsy is the final stage of the diagnostic process, which allows us to assess cell and tissue changes. Guided biopsies are performed under the control of musculoskeletal imaging methods (CT, $\mathrm{MRI}$ ) and they are the most promising tools in bone metastases diagnosis. The development of guided biopsy techniques has led to the conclusion that they should be standard in diagnosing bone metastases. Liquid biopsy (LB) seems to be the most promising diagnostic method for detection of bone metastases. LB based on tumour-specific DNA mutation gives an opportunity for early detection and assessment of the molecular heterogeneity of the overall disease.

Key words: metastases, bone, scintigraphy, computed tomography, magnetic resonance imaging, guided biopsies.

Contemp Oncol (Pozn) 2017; 21 (2): 98-103 DOI: https://doi.org/10.5114/wo.2017.68617

\section{Diagnostic methods for detection of bone metastases}

\author{
Bartosz Łukaszewski ${ }^{1}$, Jerzy Nazar ${ }^{1}$, Maciej Goch ${ }^{1}$, Marta Łukaszewska², \\ Adrian Stępiński ${ }^{1}$, Mieczysława U. Jurczyk ${ }^{3}$
}

1Department of Orthopaedics and Traumatology of the Locomotor System, Heliodor Swiecicki Clinical Hospital at the Poznan University of Medical Sciences, Poznan, Poland

${ }^{2}$ Chair of Family Medicine, Heliodor Swiecicki Clinical Hospital at the Poznan University of Medical Sciences, Poznan, Poland

${ }^{3}$ Chair of Mother and Child Health, Gynaecologic and Obstetrical University Hospital, Poznan University of Medical Sciences, Poznan, Poland

\section{Introduction}

An important property of malignant tumours is that their development is not only limited to the place from which they origin, the primary tumour, but they also have the ability to detach themselves and move to other parts of the body, where they can develop as a separate tumour. This process is called the formation of metastases [1]. Just as in primary tumours, metastases develop at the expense of local tissues, and in the case of bones they bring about pathologic fractures that cause serious complications in orthopaedic and cancer treatment.

The skeleton is the third (after the liver and lungs) most common organ to be affected by metastatic cancer [2]. A significant number of patients suffering from this disease (600 thousand new cases per year in the USA) is a challenge for modern healthcare systems [3]. Due to advances in cancer treatment, survival of patients with bone metastases increases as well. This, in turn, challenges orthopaedic oncology, which aims to provide the patient with the highest level of physical mobility while eliminating the pain associated with the development of metastatic outbreaks.

As many as $65 \%$ of all bone metastases originate from the breast in women, and from the prostate in men. The remaining 35\% arise from kidney, thyroid, and lung cancers [4]. Table 1 presents the estimated number of new cases of cancer and bone metastases on a worldwide scale.

\section{Pathophysiology of bone metastases}

In response to mechanical stress, bone normally undergoes continual remodelling. This process is based on a balanced, parallel interaction of osteoblasts and osteoclasts. The essence of this phenomenon is repetitive, with consequent reconstruction of bone matrix [8]. Bone metastasis begins when primary tumour cells detach from their place of origin, reach new bone through the blood vessels, and develop their own vasculature in a new localisation [9]. The presence of numerous growth factors, cytokines, immune cells engaged in the bone remodelling process, and the hematopoietic process within the bone make it a suitable microenvironment for the development of metastases. As a consequence of tumour cell colonisation in the bone matrix, the normal homeostasis of the bone is disrupted and the intensification of osteolytic or osteoblastic activities is reported.

\section{Clinical symptomatology}

The main complaint reported by a patient to a doctor is pain. If the location of a metastasis is a long bone (most commonly the proximal part of 
the humorous or femur) the pain is local and the patient is able to determine its scope precisely. Most commonly, pain is worse at night, unlike in osteoarthritis where pain is worse during the day and is associated with weight bearing. In the pathogenesis of pain, of crucial importance is the growth of intraosseous pressure caused by the growing tumour. When the metastasis is inserted in the pelvis or spine area, its symptomatology is more difficult because it bears a resemblance to other diseases that can be located in these places.

\section{Imaging methods in the diagnosis of metastases}

Classic X-ray (radiography) performed in 2 orthogonal projections is most often the first test performed in the early diagnosis of metastases. On the basis of X-ray one can not only obtain information on the size and location of the bone tumour, but also assess the risk of pathological fracture. X-ray allows us to determine whether the tumour is osteolytic, osteoblastic, mixed, or if there is a change due to tumour-like change similar to Paget's disease or brown tumour. Due to its accessibility and popularity, the $X$-ray examination is quick and cheap, giving it a crucial advantage. In each case, the metastatic tumour diagnosis should strive to clarify the nature of the change with the use of further imaging methods (MRI, CT) [10].

Bone scintigraphy (BS) is a method of imaging with the highest sensitivity (95\%) regarding metastases, and it is the basis of screening [11-13]. It allows the depiction of the entire skeleton in one medical examination. The scan shows intensive radionuclide activity, which in turn detects areas of bone abnormalities. The causes of bone turnovers can be different than of metastatic origin (leukaemia, healing fracture, etc.), and for this reason the low specificity of scintigraphy remains its biggest drawback.

Computed tomography $(\mathrm{CT})$ is a complementary imaging technique used to diagnose bone metastases. It is recommended particularly in dealing with discrepancies between the outcomes of X-ray (negative) and scintigraphy (positive). It allows us to establish the range of destruction of the cortical bone and the presence of periosteal reactions [14]. Obtained CT scans give the ability to determine the spatial structure and volume of metastasis. This is important in preoperative planning because it allows the appropriate selection of an orthopaedic implant [15].

Magnetic resonance imaging (MRI) is the most sophisticated method for imaging bone tumors. This technique is based on the detection of the proton content in the cells. Cancer cells contain more water molecules than healthy bone marrow or cortical bone. Diagnostic images determine not only the degree and type of the damage to the bone but also give the opportunity to assess the soft tissues adjacent to tumour $[16,17]$. During whole body MRI examination there is greater chance of diagnosing metastases, than with the use of scintigraphy. Nevertheless, this method is far less available due to equipment limitations.

Positron emission tomography (PET) is a modern and recognized method of detecting cancer cells. The use of a marker 18F-FDG is an effective way of indicating cells with the increased absorption of glucose, such as metas-
Table 1. Estimated number of new cases of cancer and bone metastases on a worldwide scale

\begin{tabular}{|lccc|}
\hline Cancer & $\begin{array}{c}\text { Five-year } \\
\text { world } \\
\text { prevalence } \\
{[5]}\end{array}$ & $\begin{array}{c}\text { Incidence } \\
\text { of bone } \\
\text { metastases in } \\
\text { cancers }[6]\end{array}$ & $\begin{array}{c}\text { Median } \\
\text { survival } \\
\text { (months) } \\
{[6,7]}\end{array}$ \\
\hline Breast & 3860000 & $65-75 \%$ & $19-25$ \\
\hline Prostate & 1555000 & $65-75 \%$ & $12-53$ \\
\hline Lung & 1394000 & $30-40 \%$ & 6 \\
\hline Melanoma & 533000 & $14-45 \%$ & 6 \\
\hline Renal & 480000 & $20-25 \%$ & 6 \\
\hline Thyroid & 475000 & $60 \%$ & 48 \\
\hline
\end{tabular}

tases. By combining PET and CT, high-resolution images can be obtained $[18,19]$. Their diagnostic value is comparable to that obtained with the use of MRI whole-body mode [20-22].

\section{Biopsies}

To take a sample of the tumour for histopathological examination the following should be performed: fine-needle aspiration biopsy (FNAB), core-needle biopsy (CNB), or open biopsy $(\mathrm{OB})$, which is a surgical treatment. Each of these three techniques is an established and widely used method of diagnosing neoplastic lesions of human bone. Each of them has its advantages and limitations. The decision about the type of biopsy performed depends on the topographic location of the tumour and the experience of the person performing the test. A biopsy should be planned on the basis of physical examination and diagnostic images (X-ray, Scintigraphy, CT, MRI, PET) in such a way that the final operative treatment could be carried out from the same operative approach as for biopsy (with the principle of opening one anatomical compartment) [23].

Fine-needle aspiration biopsy is an invasive yet safe and non-traumatic technique of excising biological material. It is the simplest and the cheapest diagnostic method, which is widely used mainly for diagnosing osteolytic metastases, mixed osteoblastic/osteolytic, and multiple metastases (samples taken from many areas). It is performed by percutaneous puncture of a tumour with a G20-G27 or smaller needle. An important limitation of this method is the significant percentage of outcomes that are falsely negative - about 20-30\% [24].

Core-needle biopsy gives the opportunity to excise biological material (tissue block) and to maintain the architecture of the tissue. It allows histopathological, immunohistochemical, structural, and molecular analysis. It is an invasive method with a much better responsiveness than FNAB, performed with the use of a stylet needle, sized 10-14 G. Core-needle biopsy can provide an accurate diagnosis in about $74 \%$ of cases $[25,26]$.

Needle biopsies can be performed under local anesthesia in an outpatient setting. They are viable and do not require patient's stay.

Open biopsy is an operative method in which biological material is obtained directly. It is performed in the operating room and is therefore limited to hospital patients 
only. This method is of the highest sensitivity and is recommended in cases in which needle biopsies were negative and a bone change is visible on imaging studies. OB should be done in orthopaedic oncology wards because it requires compliance with certain rules, such as:

- straight incision carried out centrally on a change in its long axis,

- incision carried out in such a way that it gives the possibility to perform resectable (final) surgery,

- incision made within one anatomical compartment (the principle of one compartment),

- incision distant from the neurovascular bundle,

- post-operative drain within the wound,

- accurate haemostasis [27].

Like any operative procedure, OB may bring about many complications associated primarily with post - operative bleeding, wound healing, local pain or infection.

Liquid biopsies based on genetic analysis of blood-serum and bone morrow for tumour markers. Tumour-specific mutations are used for detection of cancer cells and metastatic tumour cells [28]. Disseminated tumour cells (DTCS) are detected in bone marrow, and circulating tumour cells (CTCS) are detecting in blood serum (Fig. 1). Specific DTCs are currently identify in bone marrow for breast cancer (HER2 gen) [29], prostate cancer (PSA, MAGEcDNAs) [30], lung (monoclonal antibody CK2 against CK18) [31], colorectal (CK20- cytokeratin 20) [32], and for other epithelial tumours: gastric cancer, oesophageal cancer, head and neck carcinomas [33, 34].
Benefits of liquid biopsies:

- minimally invasive,

- easy to perform,

- repeatable,

- avoids pain for the patient.

\section{Guided biopsies}

Guided biopsies are performed under control of musculoskeletal imaging methods (CT, MRI). They are the most promising tools in bone metastasis diagnosis. After the initial imaging of the examined area (usually the spine and pelvis), a needle biopsy is used under local anaesthesia. The location of the needle tip within the tumour is confirmed by the next step of imaging examination. If the needle position is correct, the doctor draws out the material for histopathological examination. This method of biopsy minimises the risk of incorrect cell removal and is recognised as highly accurate. Life imaging guided biopsies give the opportunity to take tissue samples accurately from the growing part of the tumour (tumour-specific cells); they eliminate risk of taking necrotic tumour tissue, thus preventing false diagnoses. Its efficiency (about 78\%) increases if a core needle biopsy is used [35].

With the advance of guided biopsies, which are safe and precise, they become widely used in diagnosis and therapy (percutaneous tumour ablation, application of bone cement into the tumour) $[36,37]$. Guided biopsies with the use of CT are faster, cheaper, and more accessible diagnostic methods than those used with an MRI technique. Most patients may leave hospital alone on the same day the biopsy is performed.

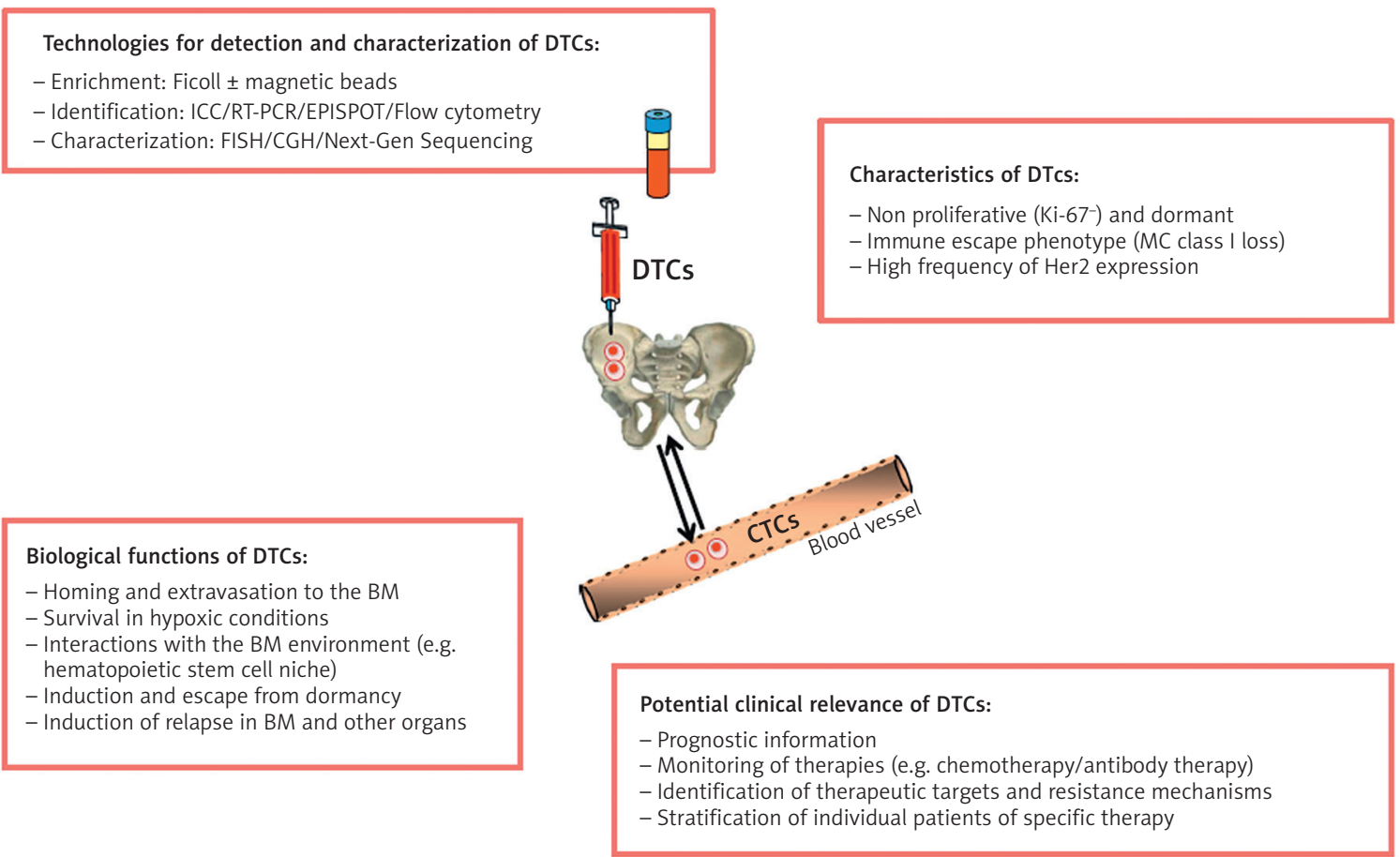

BM - bone marrow; CGH - comparative genomic hybridization; FISH - fluorescent in situ hybridization; ICC - immunocytochemistry; MHC - major histocompatibility class; $R T-P C T$ - reverse transcriptase- $P C R$

Fig. 1. Disseminated tumor cells in bone morrow. Tumor cells in the blood are denoted CTCs [28] 
Table 2. Diagnostic methods for detection of bone metastases

\begin{tabular}{|c|c|c|c|c|c|}
\hline $\begin{array}{l}\text { Diagnostic } \\
\text { method }\end{array}$ & Description & $\begin{array}{l}\text { Sensitivity and } \\
\text { specificity }\end{array}$ & Timing & Limitations & References \\
\hline X-ray & $\begin{array}{l}\text { Noninvasive, } \\
\text { available, cheap }\end{array}$ & $\begin{array}{l}\text { Sensitive in suspected } \\
\text { pathological fractures }\end{array}$ & Early diagnosis & Pelvis and spine imaging & {$[10]$} \\
\hline CT & Noninvasive & $\begin{array}{l}\text { Sensitivity ++ } \\
\text { Specificity ++ }\end{array}$ & $\begin{array}{l}\text { Early diagnosis, } \\
\text { Pre-operative planning }\end{array}$ & Implants & {$[14,15]$} \\
\hline MRI & Noninvasive & $\begin{array}{l}\text { Sensitivity +++ } \\
\text { Specificity +++ }\end{array}$ & Complementary examination & Ferromagnetic implant & {$[16,17]$} \\
\hline $\begin{array}{l}\text { Bone } \\
\text { Scintigraphy }\end{array}$ & Radionuclide isotop & $\begin{array}{l}\text { Sensitivity +++ } \\
\text { Specificity + }\end{array}$ & $\begin{array}{l}\text { Screening in patient with prior } \\
\text { organ tumor diagnosed }\end{array}$ & $\begin{array}{l}\text { Need for iv administration } \\
\text { of radioisotope }\end{array}$ & {$[11-13]$} \\
\hline FGD-PET & Radionuclide isotop & $\begin{array}{l}\text { Sensitivity +++ } \\
\text { Specificity ++ }\end{array}$ & $\begin{array}{l}\text { Screening in patient with prior } \\
\text { organ tumor diagnosed }\end{array}$ & $\begin{array}{l}\text { need for iv administration } \\
\text { of radioisotope }\end{array}$ & {$[18-20]$} \\
\hline $\begin{array}{l}\text { Whole body } \\
\text { MRI }\end{array}$ & Noninvasive & $\begin{array}{l}\text { Sensitivity +++ } \\
\text { Specificity +++ }\end{array}$ & $\begin{array}{l}\text { Screening in patient with prior } \\
\text { organ tumor diagnosed }\end{array}$ & Ferromagnetic implant & {$[21,22]$} \\
\hline FNAB & Minimally invasive & $\begin{array}{l}\text { Sensitivity } 79.17 \% \\
\text { Specificity } 72.7 \%\end{array}$ & Early ambulatory diagnosis & $\begin{array}{l}\text { No tissue structure of the } \\
\text { material }\end{array}$ & [24] \\
\hline CNB & Minimally invasive & $\begin{array}{l}\text { Sensitivity } 79.2 \% \\
\text { Specificity } 81.8 \%\end{array}$ & Early ambulatory diagnosis & $\begin{array}{l}\text { Preserved tissue structure } \\
\text { of the excised material }\end{array}$ & {$[25,26]$} \\
\hline $\mathrm{OB}$ & Invasive & $\begin{array}{l}\text { Sensitivity } 100 \% \\
\text { Specificity } 100 \%\end{array}$ & Hospital diagnosis & $\begin{array}{l}\text { Preserved tissue structure } \\
\text { of the excised material, }\end{array}$ & {$[23,27]$} \\
\hline LB & $\begin{array}{l}\text { Minimally invasive, } \\
\text { Genetic test }\end{array}$ & $\begin{array}{c}\text { Tumor specific DNA, } \\
\text { sensitivity } 100 \% \\
\text { specificity } 100 \%\end{array}$ & $\begin{array}{l}\text { Early ambulatory diagnosis, } \\
\text { monitoring, repeatable. }\end{array}$ & $\begin{array}{l}\text { Need more clinical } \\
\text { investigation. }\end{array}$ & {$[28-34]$} \\
\hline $\begin{array}{l}\text { CT/MRI guided } \\
\text { biopsy }\end{array}$ & Minimally invasive & $\begin{array}{l}\text { Sensitivity +++ } \\
\text { Specificity +++ }\end{array}$ & $\begin{array}{l}\text { Ambulatory and hospital } \\
\text { diagnosis } \\
\text { Specialist team (orthopedic } \\
\text { and radiological) }\end{array}$ & Precisely excised material & {$[35-37]$} \\
\hline Hypercalcaemia & $\begin{array}{c}\text { Minimally invasive, } \\
\text { prognostically } \\
\text { relevant }\end{array}$ & $\begin{array}{l}\text { Low sensitivity and } \\
\text { specificity }\end{array}$ & $\begin{array}{c}\text { Early diagnosis, assessment of } \\
\text { progression }\end{array}$ & & {$[38,39]$} \\
\hline
\end{tabular}

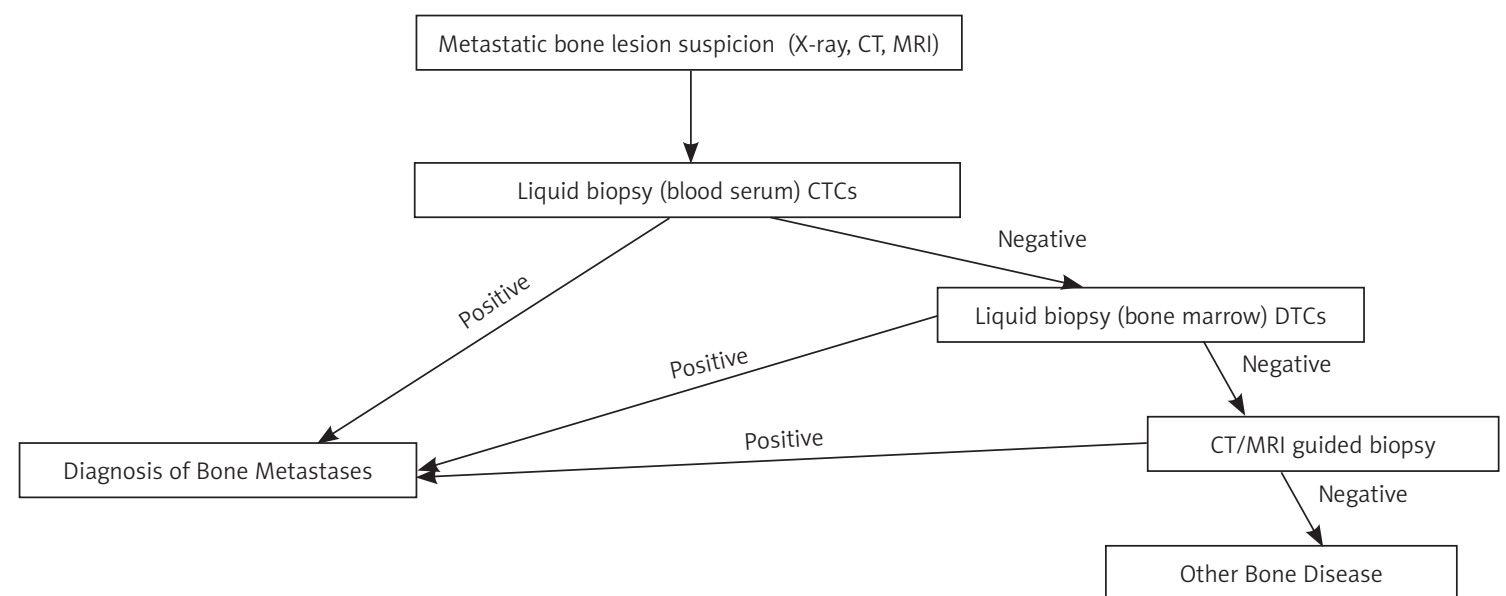

Fig. 2. Algorithm for detection of bone metastases

\section{Hypercalcaemia}

Hypercalcaemia is the most common metabolic disorder in the course of cancer (approximately 10-40\% of patients). Its development is a result of the following four mechanisms:
- local secondary osteolysis into the bone metastasis,

- the excessive release of parathyroid hormone-related protein (PTHrP),

- excessive production of 1,25-D dihydroxyvitamin,

- ectopic secretion of PTH [38].

The processes described in sections 2, 3, and 4 are associated with humoral activity of the metastatic process, 
with the main mediator of the PTHrP. Because of the presented mechanisms, there is an increase of calcium ions in serum. This, in turn, leads to clinical symptoms such as weakness, nausea, vomiting, dehydration, polyuria, abnormal heart rhythm (QT prolongation), kidney failure, anorexia, confusion, and coma. Rapidly increasing and sudden hypercalcaemia prove that there is cancer progress, and therefore the prognosis is bad [39].

\section{Summary}

The use of modern imaging techniques allows rapid diagnosis of bone metastases. Standard and well-known examinations, such as X-ray examination and bone scintigraphy, are characterised by adequate sensitivity. Thus, they remain important diagnostic tools. In the absence of correlation between clinical status (chronic pain) and radiographic image, the examinations with the highest sensitivity and specificity towards metastatic tumours are computed tomography (CT) and magnetic resonance imaging (MRI). Scintigraphy, PET, and whole body MRI enable imaging of the entire skeletal system within one examination, which makes them an important tool for bone screening in patients with previously diagnosed organ tumour (Table 2). Hypercalcaemia is a symptom of low specificity for metastatic bone disease; nevertheless, it is a significant complication in oncological treatment and worsens the prognosis of the patient. After ascertaining the presence of a tumour, due to imaging examinations, its histological verification is necessary. Optimisation of histological examination is achieved by using graphbased methods [40]. Virtual slides are checked by several image techniques: texture analysis, selection of ROI (region of interest), and pixel-derived image information [41].

A properly performed biopsy (by an orthopaedist - oncologist) determines further operative treatment. Among the options available, core needle biopsy has high sensitivity, and specificity similar to that of open biopsy. The development of guided biopsy techniques leads to the conclusion that biopsies should always be taken with life imaging (CT, MRI).

Figure 2 presents a diagnostic algorithm for bone metastases that starts from noninvasive LB (CTCS) from blood serum. In the case of a negative result a more invasive $L B$ (DTCs) from bone marrow (from iliac crest) is needed. If both LBs (blood serum and bone marrow) are negative, CT/MRI guided biopsy should be performed. Life imaging biopsies make it possible to take a proper tissue sample. Digital histopathology can be useful in analysis of the tissue sample. The algorithm can be used in clinical practice for cancer patients who have metastatic lesions and for patients that have bone lesion with unknown origin.

Liquid biopsies seem to be the most promising diagnostic method for the detection of bone metastases. Liquid biopsies enables the following: early detection, assessment of molecular heterogeneity of overall disease, monitoring of tumour dynamics, identification of genetic determinants for targeted therapy, evaluation of early treatment response, monitoring of minimal residual disease, and assessment of evaluation of resistance in real time [42]. Furthermore, technologies for isolating sufficient numbers of CTCs in blood-serum and DTCs in bone marrow are needed for every type of tumour. After that, classical invasive biopsies may be replaced by liquid biopsies.

\section{The authors declare no conflict of interest.}

\section{References}

1. Patologia. Stevens A, Lowe J (eds.). Czelej, Lublin 2000; 80.

2. Nystrom JS, Weiner JM, Heffelfinger-Juttner J. Metastatic and histologic presentations in unknown primary cancer. Semin Oncol 1977; 4: 53-8.

3. Menendez LR. OKU musculoskeletal tumors - 2002, p: 305

4. Paes FM, Serafini AN. Systemic metabolic radiopharmaceutical therapy in the treatment of metastatic bone pain. Semin Nucl Med 2010; 40: 89-104.

5. Farlay J, Bray F, Pisani P, Parkin DM. Globocan 2000, Cancer incidence, mortality and prevalence worldwide, version 1.0 IARC CancerBase No. 5. IARCPress, Lyon 2001. Available at: http://www-dep. iarc.fr/globocan/cdrom.html

6. Coleman RE. Metastatic bone disease: clinical features, pathophysiology and treatment strategies. Cancer Tret Rev 2001; 27: 165-76.

7. Coleman RE. Skeletal complications of malignancy. Cancer 1997; 80 (suppl): 1588-94.

8. Guise TA, Mundy GR, Cancer and bone. Endocr Rev 1998; 19: 18-54

9. Batson OV. The role of vertebral veins in the metastatic bone process. Ann Inter Med 1942; 16: 38.

10. Wiktora Degi ortopedia i rehabilitacja. Kruczyński J, Szulc A (eds.). Wyd. Nauk. PZWL, Warszawa 2015; 430.

11. Hamaoka T, Madawell JE, Podolof DA, Hortobagyi GN, Ueno NT. Bone imaging in metastatic breast cancer cancer. J. Clin Oncol 2004; 22: 2942-54.

12. Rieden K. Conventional imaging and computerized tomography in diagnosis of skeletal metastases. Radiologe 1995; 35: 15-20.

13. Even-SapirE, Matser U, Mishani E, Lievshitz G, Lerman H, Leibovitch I. The detection of bone metastases in patients with high-risk prostate cancer: 99mTc-MDP Planarbone scintigraphy, single- and multi-field-of-view SPECT, 18F-fluoride PET, and 18F-fluoridePET/ CT. J Nucl Med 2006; 47: 287-97.

14. Aisen AM, Martel W, Braunstein EM, McMillin KI, Phillips WA, Kling TF. MRI and CT evaluation of primary bone and soft-tissue tumors. Am J Roentgenol 1986; 146: 749-56.

15. Bone Sarcoma. Lin PP, Patel S (eds.). 2013; 22.

16. Pathak AP. Magnetic resonance imaging of tumor physiology. Methods Mol Med 2005; 124: 279-97.

17. Tehranzadeh J, Mnaymneh W, Ghavam C, Morillo G, Murphy BJ. Comaprison of CT and MR imaging in musculoskeletal neoplasms. J Comput Assist Tomogr 1989; 13: 466-72.

18. Gold LS, Lee Cl, Devine B, et al. Imaging techniques for treatment evaluation for metastatic breast cancer. Rockville (MD): Agency for Healthcare Research and Quality (US); 2014 Oct. Report No.: 14-EHCO44-EF.

19. Fogelman I, Cook G, Israel O, Van der Wall H. Positron emission tomography and bone metastases. Semin Nucl Med 2005; 35: 135-42.

20. Schmidt GP, Schoenberg SO, Reiser MF, Baur-Melnyk A. Wholebody MR imaging of bone marrow. Eur J Radiol 2005; 55: 33-40.

21. Ghanem N, Uhl M, Brink I, Schäfer O, Kelly T, Moser E, Langer M. Diagnostic value of MRI in comparison to scintigraphy, PET, MS-CT and PET/CT for the detection of metastases of bone. Eur J Radiol 2005; 55: 41-55.

22. Schmidt GP, Kramer H, Reiser MF, Glaser C. Whole-body magnetic resonance imaging and positron emission tomography-computed tomography in oncology. Top Mag Reson Imaging 2007; 18: 193-202.

23. Pohling F, Kirchhoff C, Lenze U, et al. Percutaneus core needle biopsy versus open biopsy in diagnostic of bone and soft tissue sarcoma: a retrospective study. Eur J Med Res 2012(17):29

24. Kasraein S, Alison D, Alhman E, et al. A comparison of fine-needel aspiration, core biopsy, and surgical biopsy in the diagnosis of extremity soft tissue masses. FACS Symposium highlights of the ISOLS/MSTS 2009 Meeting. 
25. Yao L, Nelson S, Seeger L, Eckardt JJ, Eilber FR. Primary Musculoskeletal Neoplasms: Effectiveness of core-needle biopsy. Radiology 1999; 212: 682-6.

26. Heslin MJ, Lewis J, Woodruss J, Brennan MF. Core needle biopsy for diagnosis of extremity soft tissue sarcoma. Ann Surg Oncol 1997; 4: 425-431.

27. Errani C, Traina F, Perna F, Calamelli C, Faldini C.Current concept in the biopsy of musculoskeletal tumors. ScientificWorldJournal 2013; 2013: 538152.

28. Pantel K, Alix-Panabières C. Bone marrow as a reservoir for disseminated tumor cells: a special source for liquid biopsy in cancer patients. Bonekey Rep 2014; 3: 584.

29. Braun S, Vogl FD, Naume B, et al. A pooled analysis of bone marrow micrometastasis in breast cancer. N Engl J Med 2005; 353: 793 802.

30. Kollermann J, Heseding B, Helpap B, et al. Comparative immunocytochemical assessment of isolated carcinoma cell in lymph nodes and bone marrow of patients with clinical localized prostate cancer. Int. J Cancer 1999; 84: 145-49.

31. Pantel K, Izbicki J, Passlick B, Angstwurm M, Häussinger K, Thetter $\mathrm{O}$, Riethmüller $\mathrm{G}$. Frequency and prognostic significance of isolated tumor cells in bone marrow of patients with non-small cell lung cancer without overt metastases. Lancet 1996; 347: 649-53.

32. Lindemann F, Schlimok G, Dirschedl P, Witte J, Riethmüller G. Prognostic significance of micrometastatic tumor cells in bone marrow of colorectal cancer patients. Lancet 1992; 340: 685-9.

33. Effenberger KE, Schroeder C, Eulenburg C, et al. Disseminated tumor cell in pancreatic cancer- an independent prognosticator of disease progression and survival. Int I Cancer 2012; 131: E475-E483.

34. Vashist YK, Effenberger KE, Vettorazzi E, Riethdorf S, Yekebas EF, Izbicki JR, Pantel K. Disseminated tumor cells in bone marrow and the natural course of resected esophageal cancer. Ann Surg 2012; 255: 1105-12.

35 Kiatisevi P, Thanakit V, Sukunthanak B, Boonthatip M, Bumrungchart S, Witoonchart K. Computed tomography-guided core needle biopsy in diagnosing musculoskeletal lesions. J Orthop Surg (Hong Kong) 2013; 21: 204-8.

36. Monfardini L, Preda L, Aurilio G, et al. CT-guided bone biopsy in cancer patients with suspected bone metastases: retrospective review of 308 procedures. Radiol Med 2014; 119: 852-60.

37. Rosenthal DI. Radiologic diagnosis of bone metastases. Cancer 1997; 80 (8 Suppl): 1595-607.

38. Clines G.A. Mechanisms and treatment of hypercalcemia of malignancy. Curr Opin Endocrinol Diabetes Obes 2011; 18: 339-46.

39. Reagan P, Pani A, Rosner MH. Approach to diagnosis and treatment of hypercalcemia in a patient with malignancy. Am J Kindney Dis 2014; 63: 141-7.

40. Sharma H, Zerbe N, Lohmann S, et al. A review of graph-based methods for image analysis in digital histopathology. Diagn Pathol 2015; DOI: http://dx.doi.org/10.17629/www.diagnosticpathology. eu-2015-1:61

41. Kayser K, Brokenfeld S, Djenouni, et al. Analysis of texture and objects in microscopic images. Diagn Pathol 2015; DOI: http://dx.doi. org/10.17629/www.diagnosticpathology.eu-2015-1:14.

42. Luis A, Diaz Jr, Bardelli A. Liquid Biopsies: Genotyping circulating tumor DNA. J Clin Oncol 2014; 32: 579-86.

\section{Address for correspondence}

\section{Bartosz Łukaszewski}

Department of Orthopedics and Traumatology of Locomotor System Heliodor Swiecicki Clinical Hospital

at the Poznan University of Medical Sciences

Przybyszewskiego 49

60-101 Poznan, Poland

e-mail: blukaszewski@gmail.com

Submitted: 20.12.2014

Accepted: $\quad 30.11 .2015$ 